\title{
Lipid Contents, Fatty Acid Profiles and Nutritional Quality of Nine Wild Caught Freshwater Fish Species of the Yangtze Basin, China
}

\author{
Zhimin Zhang ${ }^{1}$, Lianhua Liu ${ }^{2}$, Congxin Xie ${ }^{1}$, Dapeng $\mathrm{Li}^{1}$, Jun $\mathrm{Xu}^{3}$, Meng Zhang ${ }^{4}$, Min Zhang ${ }^{1, *}$ \\ ${ }^{1}$ College of Fisheries, Huazhong Agricultural University, Freshwater Aquaculture Collaborative Innovation Center of Hubei Province, \\ Wuhan, P. R. China \\ ${ }^{2}$ Key Laboratory of Pesticide and Chemical Biology of Ministry of Education, College of Chemistry, Central China Normal University, \\ Wuhan, P. R. China \\ ${ }^{3}$ Donghu Experimental Station of Lake Ecosystems, State Key Laboratory of Freshwater Ecology and Biotechnology of China, \\ Institute of Hydrobiology, Chinese Academy of Sciences, Wuhan, P. R. China \\ ${ }^{4}$ Jiangxi Academy of Environmental Sciences, Nanchang, P. R. China \\ *Corresponding author: zhm7875@mail.hzau.edu.cn
}

Received June 16, 2014; Revised July 14, 2014; Accepted July 17, 2014

\begin{abstract}
Owing to the favorable effects of essential fatty acids on human health, a great degree of interest on fatty acid profiles and nutritional quality of fish species have been of interest in the recent years. The present study investigated the lipid content, fatty acid profiles and nutritional quality in nine freshwater fish species from the Ganjiang River in the Yangtze basin, China. Results showed that total lipid content of the dorsal muscle was 0.59$2.2 \%$ and that was inversely linked to moisture content $\left(r^{2}=0.79, p<0.01\right)$. Wide ranges of monounsaturated fatty acids (MUFA) (21.83 to $50.53 \%$ ) and polyunsaturated fatty acids (PUFA) $(19.43$ to $45.60 \%)$ were found. The ratios of n-3 to n-6 PUFA ranged from 0.25 to 1.16 ( $p<0.001$ ). N-3 PUFA was dominated by eicosapentaenoic and docosahexaenoic acids varying from 2.77 to $15.11 \%$ of total fatty acids. Indices of atherogenicity and thrombogenicity (IA and IT) based on fatty acid compositions ranged from 0.36 to 0.52 and 0.36 to 0.64 in all species, respectively $(\mathrm{p}<0.001)$. These results indicated fatty acid profiles were different among the fish species and the potential of these species as dietary source of essential fatty acids from the nutritional standpoint.
\end{abstract}

Keywords: lipids, polyunsaturated fatty acids, fish, nutritional quality, Ganjiang River

Cite This Article: Zhimin Zhang, Lianhua Liu, Congxin Xie, Dapeng Li, Jun Xu, Meng Zhang, and Min Zhang, "Lipid Contents, Fatty Acid Profiles and Nutritional Quality of Nine Wild Caught Freshwater Fish Species of the Yangtze Basin, China.” Journal of Food and Nutrition Research, vol. 2, no. 7 (2014): 388-394. doi: 10.12691/jfnr-2-7-10.

\section{Introduction}

In the recent years the beneficial effects of highly unsaturated fatty acids in human nutrition has been increasingly recognized. For example such effects include its impacts on health, growth, vision among other characteristics [1,2,3]. In addition it is also thought that access to sea foods and hence the high contents of polyunsaturated fatty acids (PUFA) to our ancestors help develop the human brain, together with the acquisition of bipedalism made us what we are today [4,5]. PUFA, especially long-chain n-3 PUFA from fish or fish oil have demonstrated beneficial effects on clamping down several widespread diseases worldwide when consumed by humans according to epidemiological and statistical research [6,7].

Freshwater fish are generally characterized by low n-3 PUFA levels and high C: 18 PUFA levels compared to marine fish [8]. Fish, however, is one of the main sources of animal protein in the world, particularly among developing countries [9]. The high nutritional value of fish is also attributed to other nutritive materials and essential to humans such as minerals and vitamins [10]. Lipid contents and fatty acid compositions of fish species may differ even among different individuals of the same species. These variations result from geographical locations, dietary levels, feeding habits and other environmental factors $[10,11,12,13]$. However, freshness, availability, price and consumer preferences are important factors in the selection of fish for consumption [14,15]. Most individuals, especially residents of central and west China, consume freshwater fish as the availability and price of marine fish are relatively limited, whereas freshwater fishery and aquaculture in inland waters in China are well developed [9].

The fish species investigated in the present study are available in almost all markets nationwide and are important contributors to agricultural products exported. Although fish consumption is recommended in Chinese tradition due to its nutrients, the nutritional importance 
and difference of fish species is often neglected by consumers. Moreover, data on fatty acid profiles and nutritional quality of these fish species are limited. A few studies have been conducted on fatty acid profiles in freshwater fish obtained from aquaculture ponds and from freshwater lakes [16,17]. However, studies on wild fish from large river basins or capture fisheries such as of the Yangtze River and Yellow River are limited. These fish evidently have less natural food resources compared with fish from eutrophic lakes, reservoirs and aquaculture ponds. In view of these facts, it is necessary to evaluate the chemical compositions and nutritional values of commonly consumed wild fish species from these habitats. To the best of our knowledge, our study is the first to examine fatty acid profiles and nutritional values of wild fish species from the Ganjiang River in the Yangtze basin.

The objectives of the present work were to investigate the total lipid contents and fatty acid profiles of wild freshwater fish, to explore the nutritional differences among different fish species, and to elucidate the potential nutritional and medicinal value of fatty acid composition to consumers. These goals aim to provide specific nutritional information with respect to the consumption of wild freshwater fish for nutrient balance as foodstuff.

\section{Material and Methods}

\subsection{Sample Collection}

A total of fifty-two samples of Carassius auratus, Cyprinus carpio, Pelteobagrus fulvidraco, Megalobrama amblycephala, Siniperca chuatsi, Silurus meridoualis, Channa argus, Culter mongolicus and Channa asiatica representing five families were caught by local fishers from the Ganjiang River in the Yangtze basin, were randomly collected in May 2013. The number of each fish species analyzed and the mean-total length and somatic weight of all the specimens were recorded prior to the removal of the muscle samples for analysis. The freshly harvested fish were scaled immediately using a stainless steel knife. Skinless dorsal muscle samples were removed from the main edible portion of the fish and maintained in liquid nitrogen. All collected samples were moved after arriving at the laboratory and frozen at $-80{ }^{\circ} \mathrm{C}$ prior to lipid extraction.

\subsection{Lipid Extraction and Moisture Analysis}

Moisture content was determined by drying the samples in an oven at $105^{\circ} \mathrm{C}$ to constant weight according to AOAC method [18]. Individual muscle samples measuring approximately $2.5 \mathrm{~g}$ were cut into small pieces before lipid extraction. The extraction process followed the method utilized by Bligh and Dyer [19] with minor modifications. The samples were saturated with $12.5 \mathrm{ml}$ of chloroform/methanol/distilled water (2:2:1) containing $0.01 \%$ butylated hydroxyl toluene. Organic liquid phase was obtained after mixed-phase separation. The liquid was passed through Whatman No. 1 filter paper and dried with moderate anhydrous sodium sulfate, then concentrated by using an evaporation-condensation rotating apparatus in a $40{ }^{\circ} \mathrm{C}$ water bath. Total lipid content was gravimetrically quantified. The moisture and lipid contents were expressed in $\mathrm{g} \mathrm{kg}^{-1}$ wet weight fish muscle.

\subsection{Fatty Acid Analysis}

Fatty acids were analyzed in the form of fatty acid methyl esters (FAMEs) prepared from the extracted lipid. The lipid extract of each individsual fish was saponified with $0.5 \mathrm{M}$ sodium hydroxide in redistilled absolute methanol at $70^{\circ} \mathrm{C}$ and then the fatty acids were methylated with $14 \%$ boron trifluoride methanol solution. Redistilled n-hexane was used in the extraction of derived FAMEs once the reaction mixture cooled to room temperature. The FAMEs were separated and quantified using GC-450 (Varian, USA) equipped with a flame ionization detector and an autosampler as described below. Individual FAME identification was performed by comparing the retention times of authentic mixture standards (Nu-Chek Prep, Inc., MN, USA) which were determined by GC-450/MS-320 (Varian, USA) with a DB-23 capillary column $(0.25 \mathrm{~mm}$ i.d. $\times 0.25 \mu \mathrm{m}$ film $\times 60 \mathrm{~m}$ length, $\mathrm{J} \& \mathrm{~W}$ Scientific, USA). Oven temperature was programmed from 90 to $230^{\circ} \mathrm{C}$. The injection port and detector temperatures were 270 and $250^{\circ} \mathrm{C}$, respectively. Ultra-pure helium flowing at a rate of $1 \mathrm{ml} \mathrm{min}{ }^{-1}$ was used for each sample analysis and splitless injection of $1 \mu$ l sample was performed. The profiles of individual fatty acids were calculated using an automatic integrator and presented as percentages of total fatty acids according to the peak areas. Fatty acids in wet weight muscle were quantified according to the conversion factor of total fatty acids to total lipid content in finfish derived by [20].

\subsection{Lipid Quality Indices}

Indices of lipid quality in the fish species were estimated according to the method used by Ulbricht and Southgate [21] based on fatty acid compositions. Indices of atherogenicity (IA) and thrombogenicity (IT) were calculated by the following formulas:

$$
\begin{aligned}
& \text { IA }=[(12: 0)+(4 \times 14: 0)+(16: 0)] \times[\text { PUFA }(n-6 \text { and } \\
& n-3)+ \text { MUFA })]^{-1} \\
& \text { IT }=[(14: 0)+(16: 0)+(18: 0)] \times[(0.5 \times \text { MUFA })+ \\
& \left.(0.5 \times n-6)+(3 \times n-3)+\left(n-3 \times n-6{ }^{-1}\right)\right]^{-1} .
\end{aligned}
$$

\subsection{Statistical Analyses}

All of the data were presented as means \pm standard deviation (SD). Statistical analyses of data were conducted using SPSS statistics software (version 17.0) for Windows. The data identified as non-homogeneous by Levene's test were subjected to log transformation to confirm normal distribution and homogeneity of variance following comparison tests of experimental data prior to the statistical analyses. One-way analysis of variance (ANOVA) was used in the statistical comparisons. Fisher's least significant difference (LSD) multiplecomparison tests were applied to the mean values of sample variances. Differences were considered significant when $\mathrm{p}<0.05$.

\section{Results and Discussion}

\subsection{Total Lipid Content}

Table 1 showed biometric data and biological indices of the fish collected. Total lipid content in the freshwater fish sampled varied greatly in this study $(\mathrm{p}<0.05)$. C. argus 
had the lowest lipid content among the individual samples (4.3 $\mathrm{g} \mathrm{kg}^{-1}$ ) whereas C. asiatica had the highest lipid content $\left(27.7 \mathrm{~g} \mathrm{~kg}^{-1}\right)$. All species, except $C$. asiatica were categorized as very low fat fishes (lipid content, $<2 \%$ ) [22]. The mean lipid content of the nine fish species ranged from 5.9 to $22.0 \mathrm{~g} \mathrm{~kg}^{-1}$ and averaged $11.3 \mathrm{~g} \mathrm{~kg}^{-1}$. Two-thirds of the fish species were below $10.0 \mathrm{~g} \mathrm{~kg}^{-1}$ in lipid content (Table 1). The low lipid levels were similar to those of wild freshwater fish from Lake Taihu in China which showed a smaller scope of the lipid contents, ranging from 5 to $13 \mathrm{~g} \mathrm{~kg}^{-1}$ [17]. In contrast, Du et al. [16] reported that the lipid levels of freshwater fish from Chinese ponds had a wider range and a greater mean (9.5 to $38.5 \mathrm{~g} \mathrm{~kg}^{-1}$ and $20.4 \mathrm{~g} \mathrm{~kg}^{-1}$, respectively), meanwhile five freshwater fish species found in Indian ponds had slightly higher levels (6.0 to $25.5 \mathrm{~g} \mathrm{~kg}^{-1}$ and $12.9 \mathrm{~g} \mathrm{~kg}^{-1}$, respectively) than those in this study [23]. The results further confirmed the findings that wild fish generally have lower lipid levels than cultured fish [11,24]. However, some wild freshwater fish species from the Brazilian Pantanal exhibited high lipid contents [25]. In general, freshwater fish are typically characterized by low lipid content, although a plenty of researches have reported the effects of numerous factors on fish lipid content $[26,27,28]$. In addition, moisture content in the fresh muscles of the collected fish was notably high (Table 1). Our results revealed an inverse correlation between moisture content and total lipid $\left(\mathrm{r}^{2}<0.79\right.$, $\mathrm{p}<$ 0.01). Various studies on different types of fish reached a similar conclusion (Figure 1). Fish with relatively low moisture content had high lipid content. Moreover, this relationship was also linearly observed in farmed species and significantly in fatty fish [29].

Table 1. Biometric data and biochemical indices of nine wild freshwater fish species

\begin{tabular}{|c|c|c|c|c|c|c|}
\hline Latin name & $\mathrm{N}^{*}$ & Total length $(\mathrm{cm})$ & Standard length $(\mathrm{cm})$ & Somatic weight (g) & Moisture $\left(\mathrm{g} \mathrm{kg}^{-1}\right)$ & Total lipid $\left(\mathrm{g} \mathrm{kg}^{-1}\right)$ \\
\hline C. auratus & 8 & $19.4 \pm 4.3$ & $15.9 \pm 3.7$ & $127.0 \pm 57.4$ & $803.0 \pm 7.3$ & $7.0 \pm 3.0^{a}$ \\
\hline C. carpio & 7 & $33.2 \pm 7.6$ & $27.9 \pm 6.5$ & $765.3 \pm 607.5$ & $789.3 \pm 20.7$ & $7.8 \pm 2.3^{a}$ \\
\hline P. fulvidraco & 8 & $25.4 \pm 3.4$ & $22.0 \pm 3.0$ & $156.7 \pm 33.1$ & $779.4 \pm 14.0$ & $16.7 \pm 6.2^{b}$ \\
\hline M. amblycephala & 5 & $29.8 \pm 4.2$ & $25.7 \pm 3.7$ & $287.5 \pm 162.6$ & $784.8 \pm 5.9$ & $8.5 \pm 1.4^{\mathrm{a}}$ \\
\hline S. chuatsi & 5 & $23.4 \pm 6.0$ & $20.6 \pm 5.1$ & $180.2 \pm 152.0$ & $796.8 \pm 14.5$ & $7.1 \pm 2.4^{\mathrm{a}}$ \\
\hline S. meridoualis & 6 & $29.8 \pm 4.9$ & $27.0 \pm 5.5$ & $177.4 \pm 58.1$ & $798.3 \pm 6.9$ & $6.5 \pm 2.0^{\mathrm{a}}$ \\
\hline C. argus & 6 & $33.0 \pm 4.7$ & $28.3 \pm 4.1$ & $378.8 \pm 160.4$ & $791.5 \pm 14.0$ & $5.9 \pm 1.2^{\mathrm{a}}$ \\
\hline C. mongolicus & 4 & $43.9 \pm 5.2$ & $38.5 \pm 4.9$ & $1042.6 \pm 334.6$ & $778.5 \pm 10.1$ & $18.5 \pm 3.4^{b}$ \\
\hline C. asiatica & 3 & $28.6 \pm 1.3$ & $24.6 \pm 1.1$ & $191.4 \pm 39.6$ & $763.7 \pm 5.9$ & $22.0 \pm 6.3^{b}$ \\
\hline
\end{tabular}

*Number of samples; Values are means \pm standard deviation; Values with different letter superscripts in the column are significantly different (p $<0.05)$.

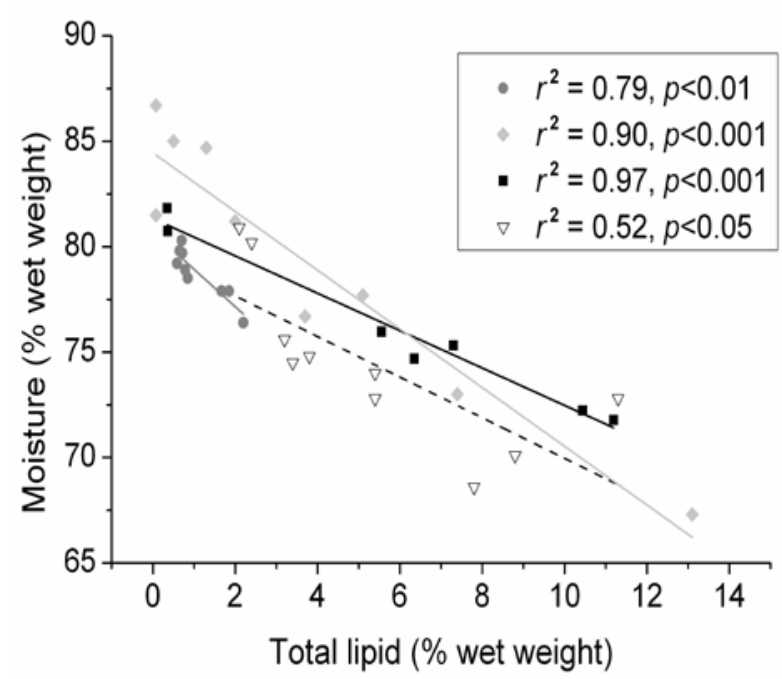

Figure 1. The relationship of total lipid and moisture content in wild freshwater fish species. Different symbols present data from different studies: $(\bullet)$ from this study including nine wild freshwater fish species; $(\diamond)$ from Usydus et al. [30] including nine marine and farmed fish species; (घ) from Ramos Filho et al. [25] including seven freshwater fish species; $(\nabla)$ from Netteton et al. [13] including wild and farmed fish species

\subsection{Fatty Acid Profiles}

Total fatty acid profiles in fish muscle were compared and listed in Table 2. Fatty acids were categorized into saturated fatty acids (SFA), which comprised 27.00 to $35.95 \%$ of total fatty acids in all fish species; monounsaturated fatty acids (MUFA), which accounted for 21.83 to $50.53 \%$; and polyunsaturated (PUFA), which constituted 19.43 to $45.60 \%$. Results revealed that the fatty acid composition profiles of the fish species investigated were markedly different. C. auratus had the highest PUFA content but the lowest MUFA. The opposite tendency was observed in $C$. asiatica and $C$. mongolicus. SFA variation was evidently smaller than those in MUFA and PUFA, although the three types of fatty acids in the present study displayed comparable mean levels (32.72, 34.47 and 32.81\%, respectively). However, the range of MUFA in the current study was larger than those reported by previous studies [17,25]. Scatter diagrams indicating the relationships between total lipid content in fish muscle and SFA, MUFA and PUFA levels in total fatty acids were given in Figure 2. Noticeable changes in SFA percentage with lipid content variation were not observed. As shown in Figure 2a, the result was consistent with the previous result that SFA content was not greatly affected by lipid variations in fish muscle [29]. MUFA percentage tended to increase when total lipid content increased (Figure 2b), whereas a negative association between total lipid content and PUFA (Figure 2c). Similar conclusion was obtained by [31], although they found a different relationship between SFA percentage and total lipid content in Australian fish. Total lipids generally consist of various lipid classes, and the proportions of different fatty acid types are reflected in various lipid compositions. Therefore, specific and individual lipid classes in fish should be investigated further to obtain additional knowledge regarding the correlation between total lipid content and fatty acid profiles. 
Table 2. Analysis of fatty acid profiles (\% of total fatty acids) in muscles of nine wild freshwater fish species

\begin{tabular}{|c|c|c|c|c|c|c|c|c|c|c|}
\hline $\mathrm{EO}^{*}$ & Fatty acid & $\begin{array}{c}\text { C. } \\
\text { auratus }\end{array}$ & $\begin{array}{c}\text { C. } \\
\text { carpio }\end{array}$ & $\begin{array}{c}P . \\
\text { fulvidraco }\end{array}$ & $\begin{array}{c}\text { M. } \\
\text { amblycephala }\end{array}$ & $\begin{array}{c}\text { S. } \\
\text { chuatsi }\end{array}$ & $\begin{array}{c}\text { S. } \\
\text { meridoualis }\end{array}$ & $\begin{array}{c}\text { C. } \\
\text { argus }\end{array}$ & $\begin{array}{c}\text { C. } \\
\text { mongolicus }\end{array}$ & $\begin{array}{c}\text { C. } \\
\text { asiatica }\end{array}$ \\
\hline 1 & C12:0 & $0.09 \pm 0.06$ & $0.20 \pm 0.11$ & $0.16 \pm 0.12$ & $0.14 \pm 0.06$ & $0.11 \pm 0.07$ & $0.14 \pm 0.05$ & $0.09 \pm 0.07$ & $0.07 \pm 0.02$ & $0.05 \pm 0.01$ \\
\hline 2 & $4: 0$ & $1.26 \pm 0.40$ & $1.87 \pm 0.83$ & $2.73 \pm 1.52$ & 1.15 & $2.06 \pm 0.48$ & $5 \pm 1.12$ & +1.41 & $1.87 \pm 0.45$ & $=0.17$ \\
\hline 4 & $5: 0$ & $0.71 \pm 0.22$ & $0.48 \pm 0.20$ & $0.57 \pm 0.22$ & $0.58 \pm 0.16$ & $55 \pm 0.13$ & $47 \pm 0.23$ & $0.55 \pm 0.23$ & $5 \pm 0.13$ & $0.27 \pm 0.02$ \\
\hline 5 & C16:0 & $20.25 \pm 1.18$ & $20.24 \pm 2.34$ & $21.87 \pm 1.23$ & $20.97 \pm 0.74$ & $23.50 \pm 1.81$ & $21.48 \pm 0.76$ & $24.27 \pm 2.44$ & $18.47 \pm 1.09$ & $24.71 \pm 0.2$ \\
\hline 7 & C17:0 & $1.19 \pm 0.31$ & $1.15 \pm 0.64$ & $0.84 \pm 0.51$ & $0.79 \pm 0.45$ & $1.19 \pm 0.43$ & $0.96 \pm 0.28$ & $0.70 \pm 0.34$ & $0.21 \pm 0.20$ & $0.28 \pm 0.02$ \\
\hline 9 & C18:0 & $8.65 \pm 1.09$ & $7.85 \pm 0.88$ & $6.22 \pm 1.72$ & $6.87 \pm 0.83$ & $8.19 \pm 1.01$ & $6.69 \pm 3.47$ & $7.79 \pm 1.77$ & $5.91 \pm 1.58$ & $6.19 \pm 0.40$ \\
\hline 15 & C20:0 & $0.39 \pm 0.13$ & $0.35 \pm 0.08$ & $0.37 \pm 0.08$ & $0.32 \pm 0.18$ & $0.42 \pm 0.21$ & $0.36 \pm 0.04$ & $0.34 \pm 0.09$ & $0.19 \pm 0.05$ & $0.24 \pm 0.02$ \\
\hline \multirow[t]{2}{*}{26} & C24:0 & $0.02 \pm 0.02$ & $0.03 \pm 0.02$ & $0.04 \pm 0.03$ & $0.04 \pm 0.02$ & $0.08 \pm 0.05$ & $0.13 \pm 0.10$ & $0.07 \pm 0.04$ & $0.02 \pm 0.01$ & $0.05 \pm 0.00$ \\
\hline & $\sum$ SFA & $32.57 \pm 1.56$ & $32.17 \pm 3.69$ & $32.79 \pm 2.89$ & $32.2 \pm 1.39$ & $36.2 \pm 2.84$ & $31.87 \pm 4.02$ & $35.95 \pm 2.79$ & $27.00 \pm 1.51$ & $33.71 \pm 0.49$ \\
\hline 3 & C14:1 & $0.03 \pm 0.05$ & $0.10 \pm 0.25$ & $0.11 \pm 0.15$ & $0.08 \pm 0.05$ & $0.09 \pm 0.07$ & $0.02 \pm 0.04$ & $0.04 \pm 0.05$ & $0.06 \pm 0.02$ & $0.02 \pm 0.01$ \\
\hline 6 & C16:1 & $2.67 \pm 1.10$ & $4.07 \pm 1.36$ & $7.16 \pm 2.16$ & $6.07 \pm 2.66$ & $4.93 \pm 1.17$ & $5.37 \pm 2.36$ & $4.37 \pm 2.61$ & $5.19 \pm 1.29$ & $6.09 \pm 0.54$ \\
\hline 8 & C17:1 & nd & $0.15 \pm 0.22$ & $0.25 \pm 0.48$ & nd & nd & nd & $0.06 \pm 0.16$ & $0.27 \pm 0.32$ & $0.28 \pm 0.05$ \\
\hline 10 & C18:1n9 & $14.19 \pm 6.63$ & $19.22 \pm 5.76$ & $29.58 \pm 5.69$ & $23.63 \pm 3.37$ & $16.76 \pm 5.01$ & $18.05 \pm 7.12$ & $20.47 \pm 8.00$ & $40.3 \pm 2.55$ & $37.26 \pm 1.23$ \\
\hline 11 & C18:1n7 & $3.72 \pm 1.12$ & $3.83 \pm 1.02$ & $2.83 \pm 1.52$ & $64 \pm$ & $3.99 \pm 0.54$ & $5.23 \pm 0.81$ & $2.92 \pm 0.78$ & $2.77 \pm 1.89$ & $1.78 \pm 0.18$ \\
\hline 16 & C20:1n9 & $1.10 \pm 0.31$ & $1.40 \pm 0.74$ & $1.43 \pm 0.62$ & $0.90 \pm 0.13$ & $0.79 \pm 0.16$ & $1.12 \pm 0.29$ & $1.24 \pm 0.40$ & $1.72 \pm 0.68$ & $1.35 \pm 0.06$ \\
\hline \multirow[t]{2}{*}{22} & $22: 1$ & $0.12 \pm 0.04$ & $0.4 \pm 0.64$ & $0.10 \pm 0.04$ & $0.13 \pm 0.13$ & $0.12 \pm 0.04$ & $0.15 \pm 0.09$ & $0.20 \pm 0.14$ & $0.22 \pm 0.06$ & $0.10 \pm 0.01$ \\
\hline & $\sum$ MUFA & $21.83 \pm 7.49$ & $29.16 \pm 5.39$ & $41.47 \pm 5.37$ & $34.45 \pm 5.53$ & $26.69 \pm 6.05$ & $29.93 \pm 8.11$ & $29.30 \pm 10.54$ & $50.53 \pm 1.52$ & $46.86 \pm 0.90$ \\
\hline 12 & C18:2n6 & $14.47 \pm 5.90$ & $10.96 \pm 5.24$ & $7.28 \pm 3.96$ & $8.19 \pm 4.37$ & $4.83 \pm 1.70$ & $7.82 \pm 5.26$ & $8.74 \pm 3.34$ & $13.84 \pm 1.79$ & $10.14 \pm 0.80$ \\
\hline 13 & C18:3n6 & $0.54 \pm 0.15$ & $0.33 \pm 0.05$ & $0.20 \pm 0.13$ & $0.20 \pm 0.08$ & $0.36 \pm 0.12$ & $0.35 \pm 0.34$ & $0.34 \pm 0.17$ & $0.21 \pm 0.14$ & $0.20 \pm 0.01$ \\
\hline 14 & C18:3n3 & $2.17 \pm 0.50$ & $1.22 \pm 0.31$ & $1.60 \pm 0.75$ & $9 \pm 0.77$ & $1.17 \pm 0.27$ & $1.76 \pm 0.78$ & $1.06 \pm 0.28$ & $1.19 \pm 0.23$ & $0.79 \pm 0.08$ \\
\hline 17 & C20:2n6 & $1.06 \pm 0.12$ & $1.12 \pm 0.32$ & $0.67 \pm 0.25$ & $0.70 \pm 0.25$ & $0.44 \pm 0.05$ & $0.78 \pm 0.29$ & $0.69 \pm$ & $0.66 \pm 0.09$ & $0.44 \pm 0.04$ \\
\hline 18 & C20:3n6 & $1.48 \pm 0.47$ & $1.44 \pm 0.41$ & $0.50 \pm 0.30$ & $1.03 \pm 0.67$ & $0.70 \pm 0.25$ & $0.85 \pm 0.35$ & $0.68 \pm 0.35$ & $0.90 \pm 0.10$ & $0.31 \pm 0.03$ \\
\hline 19 & C20:4n6 & $8.64 \pm 2.34$ & $8.89 \pm 1.94$ & $2.43 \pm 1.69$ & $6.75 \pm 2.12$ & $8.99 \pm 1.70$ & $6.50 \pm 2.26$ & $5.90 \pm 5.12$ & $1.72 \pm 0.77$ & $0.63 \pm 0.10$ \\
\hline 20 & C20:3n3 & $0.28 \pm 0.09$ & $0.21 \pm 0.05$ & $0.40 \pm 0.26$ & $0.23 \pm 0.08$ & $0.23 \pm 0.05$ & $0.56 \pm 0.27$ & $0.21 \pm 0.11$ & $0.12 \pm 0.06$ & $0.19 \pm 0.01$ \\
\hline 21 & C20:5n3 & $4.03 \pm 1.54$ & $2.93 \pm 1.35$ & $2.90 \pm 1.14$ & $2.58 \pm 0.52$ & $3.61 \pm 0.96$ & $3.57 \pm 1.46$ & $1.93 \pm 0.75$ & $0.63 \pm 0.09$ & $0.63 \pm 0.17$ \\
\hline 23 & $\mathrm{C} 22: 2 \mathrm{n} 6$ & $0.02 \pm 0.02$ & $0.08 \pm 0.05$ & $0.04 \pm 0.03$ & $0.05 \pm 0.08$ & $0.01 \pm 0.03$ & $0.05 \pm 0.05$ & $0.03 \pm 0.06$ & $0.01 \pm 0.01$ & $0.06 \pm 0.03$ \\
\hline 24 & $\mathrm{C} 22: 4 \mathrm{n} 6$ & $1.04 \pm 0.14$ & $1.00 \pm 0.31$ & $0.62 \pm 0.54$ & $0.81 \pm 0.26$ & $0.89 \pm 0.27$ & $0.82 \pm 0.21$ & $1.05 \pm 0.99$ & $0.27 \pm 0.19$ & $0.2 \pm 0.02$ \\
\hline 25 & C22:5n6 & $1.82 \pm 0.37$ & $2.03 \pm 0.84$ & $0.84 \pm 0.68$ & $2.29 \pm 1.14$ & $2.44 \pm 0.43$ & $1.21 \pm 0.43$ & $1.33 \pm 0.99$ & $0.40 \pm 0.19$ & $0.2 \pm 0.04$ \\
\hline 27 & $\mathrm{C} 22: 5 \mathrm{n} 3$ & $2.17 \pm 0.86$ & $1.77 \pm 0.71$ & $1.72 \pm 0.76$ & $1.59 \pm 0.58$ & $2.19 \pm 0.36$ & $2.40 \pm 1.03$ & $2.42 \pm 0.86$ & $0.36 \pm 0.13$ & $1.73 \pm 0.01$ \\
\hline \multirow[t]{6}{*}{28} & $\mathrm{C} 22: 6 \mathrm{n} 3$ & $7.90 \pm 2.38$ & $6.69 \pm 2.36$ & $6.53 \pm 1.31$ & $7.14 \pm 2.41$ & $11.25 \pm 3.28$ & $11.53 \pm 4.63$ & $10.37 \pm 3.96$ & $2.14 \pm 0.83$ & $3.90 \pm 0.71$ \\
\hline & $\sum$ PUFA & $45.60 \pm 6.53$ & $38.67 \pm 2.12$ & $25.74 \pm 4.43$ & $33.35 \pm 6.33$ & $37.11 \pm 4.12$ & $38.20 \pm 6.76$ & $34.75 \pm 8.66$ & $22.47 \pm 2.80$ & $19.43 \pm 0.45$ \\
\hline & $\sum n-3$ & $16.55 \pm 5.01$ & $12.82 \pm 4.32$ & $13.15 \pm 3.33$ & $13.32 \pm 3.51$ & $18.45 \pm 3.90$ & $19.83 \pm 5.90$ & $15.99 \pm 4.59$ & $4.45 \pm 1.00$ & $7.24 \pm 0.93$ \\
\hline & $\sum n-6$ & $29.06 \pm 5.28$ & $25.84 \pm 4.01$ & $12.59 \pm 3.71$ & $20.02 \pm 7.46$ & $18.67 \pm 1.35$ & $18.37 \pm 5.39$ & $18.76 \pm 7.06$ & $18.02 \pm 2.25$ & $12.19 \pm 0.69$ \\
\hline & EPA + DHA & $11.93 \pm 3.76$ & $9.62 \pm 3.68$ & $9.43 \pm 1.59$ & $9.72 \pm 2.70$ & $14.86 \pm 4.06$ & $15.11 \pm 5.30$ & $12.30 \pm 4.22$ & $2.77 \pm 0.90$ & $4.53 \pm 0.88$ \\
\hline & $\sum n-3 / \sum n-6$ & $0.60 \pm 0.27$ & $0.52 \pm 0.23$ & $1.14 \pm 0.41$ & $0.74 \pm 0.28$ & $0.99 \pm 0.22$ & $1.16 \pm 0.41$ & $1.00 \pm 0.55$ & $0.25 \pm 0.06$ & $0.59 \pm 0.42$ \\
\hline
\end{tabular}

* Elution order of fatty acids; nd, not detected; Values are means \pm standard deviation

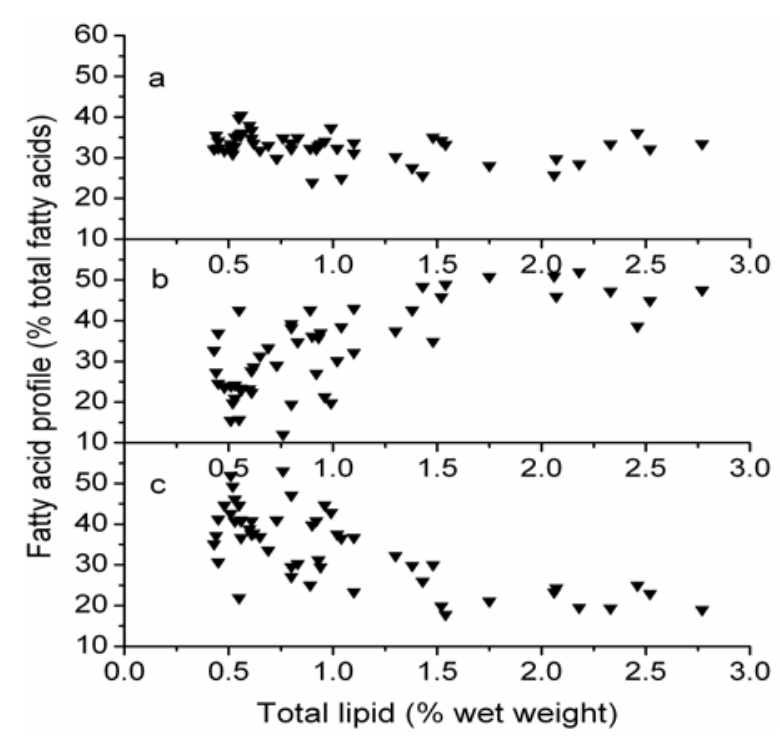

Figure 2. The relationship of total lipid content and SFA, MUFA and PUFA profiles in wild freshwater fish species. Different small letters present different types fatty acids: (a) SFA, (b) MUFA and (c) PUFA, respectively

Among SFA, the abundant fatty acids were palmitic (C16:0, 18.74 to $24.71 \%)$ and stearic (C18:0, 5.91 to
$8.65 \%$ ) acid which were in the range of freshwater fish from Turkish (14.52 to $24.74 \%$ and 5.63 to $14.80 \%$, respectively) [27]. The sum of the proportion of the two fatty acids to SFA was above $85.72 \%$ of the ratio of minimum found in $P$. fulvidraco among all the species analyzed, but more in Malaysian freshwater fish [32]. In terms of individual fatty acid in the current study, oleic acid (C18:1n9, 24.38\%) was the dominant component in both MUFA and total fatty acids, followed by palmitoleic acid (C16:1, 5.10\%). The same authors found the similar levels of oleic and palmitoleic acid (C18:1n9, 23\% and C16:1, 4.61\%, respectively), however, cis-vaccenic acid (C18:1n7, 0.13\%) was not detected in most fish species, and the mean levels determined were significantly lower than those of fish examined in the current study (C18:1n7, $3.41 \%$ ) [32]. Meanwhile, cis-vaccenic acid in fish was not reported in numerous studies [27,31,33]. This may be attributed to cis-vaccenic acid content low enough to be detected. However, it may also be a consequence of common elution with isomers that were not well resolved by some chromatographic columns [28]. The other individual MUFA was characterized by extremely low composition profiles which were below eicosenoic acid level (C20:1n9, 1.72\%) for C. mongolicus. PUFA tested in these wild fish were composed of 13 fatty acids. The 
predominant fatty acids were linoleic (C18:2n6), $\alpha$ linolenic (C18:3n3), docosahexaenoic (DHA, C22:6n3), arachidonic (AA, C20:4n6) and eicosapentaenoic (EPA, C20:5n3) acid. The highest share of these fatty acids was observed in C. auratus (C18:2n6, 14.47\%) which was in the range of the wild and cultured $C$. auratus $(11.41 \%$ and $17.00 \%$, respectively) [34]. AA constituted $8.99 \%$ and $5.90 \%$ of the total fatty acids in S. chuatsi and C. argus whereas the values $(4.8 \%$ and $3.6 \%$, respectively) obtained by [34] were significantly different from those determined in our study. The sum of two valuable fatty acids EPA and DHA varied from $2.77 \%$ in C. mongolicus to $15.11 \%$ in $S$. meridoualis. The mean value for all species was $10.03 \%$, accounting for $73.6 \%$ of the $n-3$ PUFA that was extremely close to the result (72.8\%) reported by [17]. The high ratio was obviously linked to the relatively high DHA composition profiles in $n-3$ PUFA. The proportions of DHA to total fatty acids extracted from muscle tissue substantially exceeded that of EPA in all of the tested fish species. Typically, the lowest percentage share of EPA was $0.63 \%$ obtained from both $C$. mongolicus and C. asiatica. The current study, to our knowledge, was the first to report the fatty acid profiles of the two species for preliminarily chemical composition data. The results, to some extent, appeared to account for the relatively low AA proportions in $C$. mongolicus and C. asiatica as a result of decreasing competitive inhibition from AA to eicosanoids caused by low n-3 PUFA levels, especially extremely low EPA and DHA contents [35]. Additional nutritional data and dynamic research of fish species are required.

Nutritional composition indices are important in determining the $n-3 / n-6$ PUFA ratio. All ratios ranging from 0.25 to 1.16 were similar to those of Polish freshwater fish [30] and comparable to those of most Malaysian freshwater fish [32] and those calculated by [34] but lower than those detected in wild fish by [17] which varied from 1.0 to 2.5 . This discrepancy was greatly attributed to the dependence on the available food base of the location where the fish were caught and other environmental factors. Some differences in the optimal ratio recommendations for healthy human diets are also reported. Sargent [36] recommended an optimal ratio of 0.2. However, Simopoulos [37] indicated that optimal ratio may vary in consideration of complexities and differences of disease, and the $n-3 / n-6$ ratio range of 0.25 to 1.0 was proposed as a dietary intake standard. Considering the nutritional benefits, The Food and Agriculture Organization and the World Health Organization suggested a high ratio of $>0.2$ [38]. Thus, the results from this study were in accordance with the recommended values above and indicate that these fish species are a good food selection for consumption.

\subsection{Specific Fatty Acid Quantity in Muscle}

The expression of fatty acid quantities in fish is desirable as a reference for human dietary intake. Table 3 showed the fatty acid amounts expressed as mg $100 \mathrm{~g}^{-1}$ wet weight fish muscle. The relatively high amounts of SFA, MUFA, and PUFA were in C. asiatica at 643.0, 899.9 and $369.8 \mathrm{mg} 100 \mathrm{~g}^{-1}$ fish muscle tissue, followed by those in $P$. fulvidraco and C. mongolicus. C. argus had low fatty acid amounts, followed by $S$. meridoualis and $C$. auratus. N-3 PUFA content in $P$. fulvidraco with the highest DHA and EPA concentrations was evidently higher than those in other fish species. In combination with composition profiles, to some extent, it is easily observed that the amounts of fatty acids have a positive relationship with the lipid content of fish [25]. The quantities of DHA and EPA in $S$. chuatsi and $S$. meridoualis were 77.8 and $69.1 \mathrm{mg} 100 \mathrm{~g}^{-1}$ wet weight, respectively, but lower than that in C. asiatica $(84.1 \mathrm{mg}$ $100 \mathrm{~g}^{-1}$ ) and higher than those in M. amblycephala and $C$. auratus (64.4 and $55.9 \mathrm{mg} 100 \mathrm{~g}^{-1}$, respectively). However, EPA concentration of these wild freshwater fish species

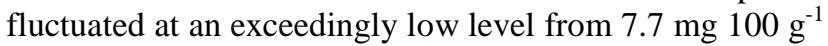
in C. argus to $19.1 \mathrm{mg} 100 \mathrm{~g}^{-1}$ in C. auratus apart from $P$. fulvidraco. This indicated that EPA from these fish is inferior to DHA as nutritional supplement in human diet.

\begin{tabular}{|c|c|c|c|c|c|c|c|c|c|}
\hline Fatty acids & $\begin{array}{c}\text { C. } \\
\text { auratus }\end{array}$ & $\begin{array}{c}\text { C. } \\
\text { carpio }\end{array}$ & $\begin{array}{c}P . \\
\text { fulvidraco }\end{array}$ & $\begin{array}{c}\text { M. } \\
\text { amblycephala }\end{array}$ & $\begin{array}{c}\text { S. } \\
\text { chuatsi }\end{array}$ & $\begin{array}{c}\text { S. } \\
\text { meridoualis }\end{array}$ & $\begin{array}{c}C . \\
\text { argus }\end{array}$ & $\begin{array}{c}\text { C. } \\
\text { mongolicus }\end{array}$ & $\begin{array}{c}\text { C. } \\
\text { asiatica }\end{array}$ \\
\hline$\sum \mathrm{SFA}$ & $164.5 \pm 86.0$ & $182.2 \pm 54.8$ & $464.1 \pm 197.4$ & $210.5 \pm 46.5$ & $185.3 \pm 78.3$ & $145.7 \pm 50.9$ & $146.2 \pm 38.8$ & $430.1 \pm 96.3$ & $643.0 \pm 192.1$ \\
\hline$\sum$ MUFA & $122.0 \pm 118.1$ & $177.3 \pm 92.1$ & $594.0 \pm 259.5$ & $226.0 \pm 62.2$ & $138.3 \pm 74.6$ & $143.4 \pm 80.0$ & $121.3 \pm 64.7$ & $805.2 \pm 178.0$ & $899.9 \pm 291.9$ \\
\hline$\sum$ PUFA & $220.8 \pm 90.6$ & $223.4 \pm 77.7$ & $358.6 \pm 144.9$ & $215.7 \pm 55.0$ & $191.9 \pm 91.9$ & $180.9 \pm 83.7$ & $139.2 \pm 41.4$ & $351.6 \pm 49.6$ & $369.8 \pm 106.9$ \\
\hline$n-6$ & $142.6 \pm 69.6$ & $155.7 \pm 75.2$ & $177.4 \pm 84.8$ & $127.6 \pm 41.4$ & $95.3 \pm 40.8$ & $89.3 \pm 55.4$ & $74.3 \pm 27.8$ & $281.4 \pm 31.6$ & $234.1 \pm 75.8$ \\
\hline$n-3$ & $78.2 \pm 43.1$ & $67.6 \pm 13.7$ & $181.2 \pm 73.5$ & $88.1 \pm 33.2$ & $96.6 \pm 53.7$ & $91.6 \pm 46.8$ & $64.9 \pm 22.6$ & $70.2 \pm 21.2$ & $135.7 \pm 33.7$ \\
\hline EPA & $19.1 \pm 12.7$ & $14.9 \pm 4.1$ & $40.9 \pm 28.3$ & $16.9 \pm 4.9$ & $18.3 \pm 9.8$ & $15.3 \pm 4.8$ & $7.7 \pm 3.0$ & $9.9 \pm 2.2$ & $11.6 \pm 2.6$ \\
\hline DHA & $36.8 \pm 18.7$ & $35.0 \pm 6.7$ & $87.6 \pm 27.0$ & $47.5 \pm 22.9$ & $59.5 \pm 37.6$ & $53.7 \pm 33.7$ & $42.2 \pm 18.2$ & $34.2 \pm 16.6$ & $72.5 \pm 17.4$ \\
\hline $\mathrm{EPA}+\mathrm{DHA}$ & $55.9 \pm 30.1$ & $49.9 \pm 10.4$ & $128.4 \pm 44.3$ & $64.4 \pm 26.6$ & $77.8 \pm 47.3$ & $69.1 \pm 37.6$ & $49.9 \pm 19.6$ & $44.1 \pm 18.4$ & $84.1 \pm 19.9$ \\
\hline
\end{tabular}

"* Results are expressed mg fatty acids per $100 \mathrm{~g}$ wet fish muscle; Values are means \pm standard deviation

\subsection{Nutritional Quality Assessment}

Due to relatively high amounts of EPA and DHA found in fish, investigations and explanatory trials on these compounds associated prevention and treatment of chronic conditions have been conducted for recent decades. On one hand, EPA and DHA intake from fish consumption is negatively related to the onset of diseases such as coronary heart disease (CHD) in numerous studies [6]. Mozaffarian and Rimm [39] recommended daily fatty acids intake of approximately $250 \mathrm{mg}$ for the general population. Compared to wild fish species analyzed in this study with respect to EPA and DHA contents, $P$. fulvidraco is a better option (Table 3). One $200 \mathrm{~g}$ portions of $P$. fulvidraco daily could meet the requirements for EPA and DHA, and other fish would be asked to more consumption by persons. However, it is unfavorable compared with most marine fish, such as Baltic salmon and herring [30]. But consumption of these wild fish is still recommended to boost health because other animal foodstuffs such as pork, lamb and beef provide little-to-no contribution in this aspect provided that equal quality 
intake. On the other hand, IA and IT are widely applied to assess nutritional quality based on fatty acid profiles $[40,41,42]$. Figure 3 showed that there was a significant difference in both the indices across fish species $(\mathrm{p}<$ 0.001). The highest IA and IT values in this study were 0.52 in C. argus and 0.64 in C. asiatica, the lowest value was 0.36 in $C$. mongolicus and $S$. meridoualis, respectively. High IA and IT values have adverse effects on human health and are considered to be important factors in underlying CHD risk increase, where the higher the values the more likely the food quality is to be degraded [21]. Increased risk of subsequent Ischemic heart disease is also related to either high IA or IT value [42]. Both of the indices in our study revealed the potential high-quality food for these fish species. The average values of IA and IT from the nine fish species were 0.45 and 0.47 , respectively. These values were similar to the mean values of two kinds of the most popularly freshwater fish Hypophthalmichthys nobilis and Ctenopharyngodon idellus in Asia (0.46 and 0.48, respectively) [43]. Meanwhile, the indices were lower than those of seven freshwater fish obtained from the Brazilian Pantanal and were comparable with those of commonly consumed freshwater fish from different countries [25]. Higher IA and IT values in chicken and beef were determined than those from fish in current study [21]. Therefore, fish should not only be considered a popular food because of its culinary properties but also for its health benefits which participate in the prevention and support of medical therapies for chronic conditions. A negative effect sometimes is imposed by accumulative persistent organic pollutants (PCBs and PEDDs) or other toxic chemicals in fish with environmental destruction [44]. Thus, this issue also requires attention, and further study on these subjects is urgent and necessary [45].

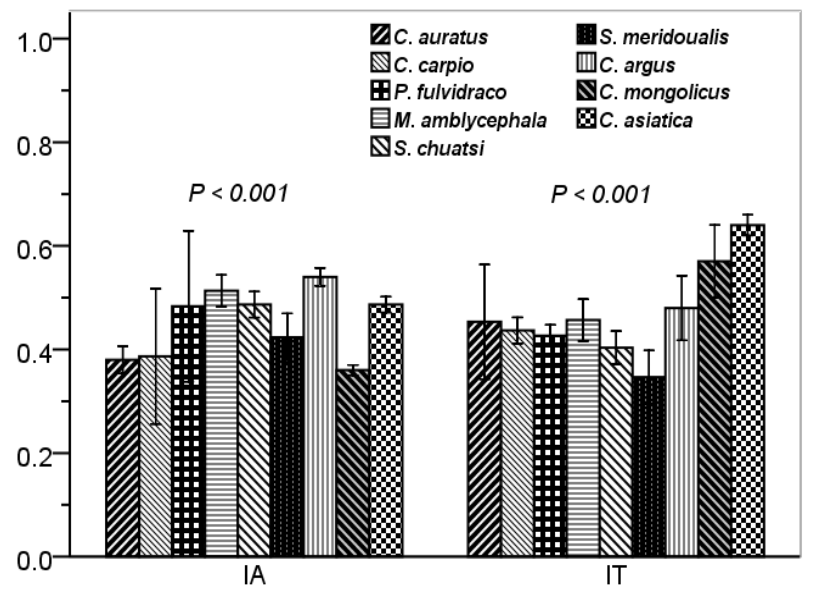

Figure 3. Indices of atherogenicity and thrombogenicity (IA and IT) based on fatty acid compositions of nine wild freshwater fish species

\section{Conclusion}

Nutritional information regarding fatty acid compositions and nutritional quality for total lipids in nine wild freshwater fish species from China was provided in our study in response to the limited knowledge on this topic. This study revealed that the muscles of all fish species analyzed were characterized by relatively high moisture and low lipid content and significant negative correlations were observed despite differences in species. MUFA and PUFA were positively and negatively correlated with total lipid content, respectively, whereas an indiscernible trend was observed in saturated fatty acids, indicating that a dynamic interaction exists between them what is needed for more attentions in the future. In perspective of nutritional value of these fish species, our results would suggest that these fish are an effective source of essential fatty acids, especially DHA in the diet and reveal that all fish species are a good functional food for the potential health benefits in disease prevention.

\section{Acknowledgement}

The study was funded by a sub-project "Water Ecological Function Areas Management and Demonstration Research of invigorated river basin" of Water Pollution Control and Treatment National Science and Technology Major Project (2012ZX07501001-06), the Key Projects in the National Science \& Technology Pillar Program during the Twelfth Five-Year Plan Period (2012BAD25B04), the Special Fund for Agro-Scientific Research in the Public Interest Project (Grant No. 201203083), the Fundamental Research Funds for the Central Universities (Grant No. 2013PY078) and the National Natural Science Foundation of China (Grant No. 31200359).

\section{References}

[1] Siriwardhana, N., Kalupahana, N.S., and Moustaid-Moussa, N. 2012. Health benefits of n-3 polyunsaturated fatty acids: eicosapentaenoic acid and docosahexaenoic acid. Adv. Food Nutr. Res. 65: 211-222.

[2] Benitez-Santana, T., Masuda, R., Juárez Carrillo, E., Ganuza, E., Valencia, A., Hernández-Cruz, C.M., and Izquierdo, M.S. 2007. Dietary n-3 HUFA deficiency induces a reduced visual response in gilthead seabream (Sparus aurata) larvae. Aquaculture. 264: 408417.

[3] Gogus, U., and Smith, C. 2010. n-3 Omega fatty acids: a review of current knowledge. Int. J. Food Sci. Tech. 45: 417-436.

[4] Leonard, W.R., Snodgrass, J.J., and Robertson, M.L. 2007. Effects of brain evolution on human nutrition and metabolism. Annu. Rev. Nutr. 27: 311-327.

[5] Broadhurst, C.L., Cunnane, S.C., and Crawford, M.A. 1998. Rift Valley lake fish and shellfish provided brain-specific nutrition for early Homo. Bri. J. Nutr. 79: 3-21.

[6] He, K., Song, Y., Daviglus, M. L., Liu, K., Van Horn, L., Dyer, A. R., and Greenland, P. 2004. Accumulated evidence on fish consumption and coronary heart disease mortality a meta-analysis of cohort studies. Circulation. 109: 2705-2711.

[7] Singh, R.B., Niaz, M.A., Sharma, J.P., Kumar, R., Rastogi, V., and Moshiri, M. 1997. Randomized, double-blind, placebocontrolled trial of fish oil and mustard oil in patients with suspected acute myocardial infarction: the Indian experiment of infarct survival-4. Cardiovasc. Drug Ther. 11: 485-491.

[8] Steffens, W. 1997. Effects of variation in essential fatty acids in fish feeds on nutritive value of freshwater fish for humans. Aquaculture. 151: 97-119.

[9] FAO. 2009. The State of World Fisheries and Aquaculture 2008. United Nations Food and Agriculture Organization, Rome.

[10] Manirujjaman, M., Khan, M.M.H., Meftah Uddin, Minarul Islam, Matiar Rahman, Khatun, M., Shahangir Biswas, and Islam, M.A. 2014. Comparison of Different Nutritional Parameters and Oil Properties of Two Fish Species (Catla catla and Cirrhinus cirrhosus) from Wild and Farmed Sources Found in Bangladesh. J. Food Nutr. Res. 2: 47-50.

[11] Grigorakis, K., Alexis, M.N., Taylor, K., and Hole, M. 2002. Comparison of wild and cultured gilthead sea bream (Sparus 
aurata); composition, appearance and seasonal variations. Int. J. Food Sci. Tech. 37: 477-484.

[12] Støttrup, J., Jacobsen, C., Tomkiewicz, J., and Jarlbæk, H. 2013. Modification of essential fatty acid composition in broodstock of cultured European eel Anguilla anguilla L. Aquacult Nutr. 19: 172-185.

[13] Nettleton, J.A., and Exler, J. 1992. Nutrients in Wild and Farmed Fish and Shellfish. J. Food Sci. 57: 257-260.

[14] Claret, A., Guerrero, L., Aguirre, E., Rincón, L., Hernández, M.D., Martínez, I., Benito Peleteiro, J., Grau, A., and RodríguezRodríguez, C. 2012. Consumer preferences for sea fish using conjoint analysis: Exploratory study of the importance of country of origin, obtaining method, storage conditions and purchasing price. Food Qual. Prefer. 26: 259-266.

[15] Verbeke, W., Sioen, I., Brunsø, K., De Henauw, S., and Van Camp, J. 2007. Consumer perception versus scientific evidence of farmed and wild fish: exploratory insights from Belgium. Aquacult. Int. 15: 121-136.

[16] Du, Z.Y., Zhang, J., Wang, C., Li, L., Man, Q., Lundebye, A.K. and Frøyland, L. 2012. Risk-benefit evaluation of fish from Chinese markets: Nutrients and contaminants in 24 fish species from five big cities and related assessment for human health. Sci. Total Environ. 416: 187-199.

[17] Zhang, D.P., Zhang, X.Y., Yu, Y.X., Li, J.L., Yu, Z.Q., Wang D.Q., Wu, D.Q., Sheng, G.Y., and Fu, J.M. 2012. Intakes of omega-3 polyunsaturated fatty acids, polybrominated diphenyl ethers and polychlorinated biphenyls via consumption of fish from Taihu Lake, China: A risk-benefit assessment. Food Chem. 132 975-981.

[18] AOAC. 1990. Association of official analytical chemists, official methods of analysis, 15th ed. AOAC, Washington, DC.

[19] Bligh, E.G., and Dyer, W.J. 1959. A rapid method of total lipid extraction and purification. Can. J. Biochem. Phy. 37: 911-917.

[20] Weihrauch, J.L., Posati, L.P., Anderson, B.A., and Exler, J. 1977. Lipid conversion factors for calculating fatty acid contents of foods. J. Am. Oil Chem. Soc. 54: 36-40.

[21] Ulbricht, T., and Southgate, D. 1991. Coronary heart disease: seven dietary factors. Lancet. 338: 985-992.

[22] Ackman, R.G. 1994. Seafood lipids. Blackie Academic and Professional, London.

[23] Ackman, R.G., McLeod, C., Misra, K.K., and Rakshit, S. 2002. Lipids and fatty acids of five freshwater food fishes of India. J. Food Lipids. 9: 127-145.

[24] González, S., Flick, G., O’keefe, S., Duncan, S., McLean, E., and Craig, S. 2006. Composition of farmed and wild yellow perch (Perca flavescens). J. Food Compos. Anal. 19: 720-726.

[25] Ramos Filho, M.M., Ramos, M.I.L., Hiane, P.A., and De Souza, E.MT. 2010. Nutritional value of seven freshwater fish species from the Brazilian pantanal. J. Am. Oil Chem. Soc. 87: 1461-1467.

[26] Kinsella, J., Shimp, J., Mai, J., and Weihrauch, J. 1977. Fatty acid content and composition of freshwater finfish. J. Am. Oil Chem. Soc. 54: 424-429.

[27] Özogul, Y., Özogul, F., and Alagoz, S. 2007. Fatty acid profiles and fat contents of commercially important seawater and freshwater fish species of Turkey: A comparative study. Food Chem. 103: 217-223.
[28] Rasoarahona, J.R., Barnathan, G., Bianchini, J.P., and Gaydou, E.M. 2005. Influence of season on the lipid content and fatty acid profiles of three tilapia species (Oreochromis niloticus, O. macrochir and Tilapia rendalli) from Madagascar. Food Chem. 91 683-694.

[29] Palmeri, G., Turchini, G.M., and De Silva, S.S. 2007. Lipid characterisation and distribution in the fillet of the farmed Australian native fish, Murray cod (Maccullochella peelii peelii). Food Chem. 102: 796-807.

[30] Usydus, Z., Szlinder-Richert, J., Adamczyk, M., and Szatkowska, U. 2011. Marine and farmed fish in the Polish market: Comparison of the nutritional value. Food Chem. 126: 78-84.

[31] Belling, G., Abbey, M., Campbell, J., and Campbell, G. 1997. Lipid content and fatty acid composition of 11 species of Queensiand (Australia) fish. Lipids. 32: 621-625.

[32] Rahnan, S.A., Huah, T.S., Nassan, O., and Daud, N.M. 1995. Fatty acid composition of some Malaysian freshwater fish. Food Chem. 54: $45-49$.

[33] Osman, H., Suriah, A., and Law, E. 2001. Fatty acid composition and cholesterol content of selected marine fish in Malaysian waters. Food Chem. 73: 55-60.

[34] Li, G., Sinclair, A.J., and Li, D. 2011. Comparison of lipid content and fatty acid composition in the edible meat of wild and cultured freshwater and marine fish and shrimps from China. J. Agric. Food Chem. 59: 1871-1881.

[35] Lands, W.E. 1986. Fish and human health. Academic Press Inc., Orlando.

[36] Sargent, J. 1997. Fish oils and human diet. Brit. J. Nutr. 78: S5.

[37] Simopoulos, A.P. 2008. The importance of the omega-6/omega-3 fatty acid ratio in cardiovascular disease and other chronic diseases. Exp. Biol. Med. 233: 674-688.

[38] FAO/WHO. 1994. Fats and oils in human nutrition. Report of a joint FAO/WHO expert consulation, 19-26 October 1993, Rome.

[39] Mozaffarian, D., and Rimm, E.B. 2006. Fish intake, contaminants, and human health. J. Am. Med. Assoc. 296: 1885-1899.

[40] Subhadra, B., Lochmann, R., Rawles, S., and Chen, R. 2006 Effect of dietary lipid source on the growth, tissue composition and hematological parameters of largemouth bass (Micropterus salmoides). Aquaculture. 255: 210-222.

[41] Delfieh, P., Rezaei, M., Hosseini, H., Vali Hosseini, S., Zohrehbakhsh, E., and Regenstein, J.M. 2013. Effects of cooking methods on proximate composition and fatty acids profile of Indian white prawn (Fenneropenaeus indicus). J. Aquat. Food Prod. T. 22: 353-360

[42] Fehily, A., Pickering, J., and Yarnell, J. 1994. Dietary indices of atherogenicity and thrombogenicity and ischaemic heart disease risk: the Caerphilly Prospective Study. Brit. J. Nutr. 71: 249-257.

[43] Hoseini, M., Baboli, M., and Sary, A. 2013. Chemica composition and fatty acids profile of farmed Big head carp (Hypophthalmichthys nobilis) and Grass carp (Ctenopharyngodon idella) filet. AACL Bioflux 6: 202-210.

[44] Rasmussen, R.S., Nettleton, R., and Morrissey, M.T. 2005. A review of mercury in seafood. J. Aquat. Food Prod. T. 14: 71-100.

[45] Zhang, Z., Zhang, M., Xu, J., and Li, D. 2014. Balanced fatty acid intake benefits and mercury exposure risks: An integrated analysis of Chinese commercial freshwater fish and potential guidelines for consumption. Hum. Ecol. Risk Assess. 